\section{Paisagens rurais - desenvolvimento e desenho a partir da decolonialidade}

\section{Rural landscapes - development and design based on decoloniality}

\author{
João Roberto Barros II \\ https://orcid.org/0000-0003-0324-7079 \\ Universidade Federal da Integração \\ Latinoamericana \\ joao.barros@unila.edu.br

\section{Lucas Monte} \\ (iD) https://orcid.org/0000-0003-1300-7140 \\ Universidade Federal da Integração \\ Latinoamericana \\ lgp.monte.2017@unila.edu.br
}

DOI: 10.22481/odeere.v5i10.7306

\section{RESUMO:}

Buscamos, primeiramente, abordar o conceito de desenvolvimento na colonialidade, com ênfase nas diversas formas de colonialidade direcionadas à destruição da natureza e de modos de vida não dualistas. A partir disso, resgatamos a noção de desenho em Arturo Escobar que compara ontologia relacional e dualista, relacionando esses conceitos ao desenvolvimento na colonialidade, à destruição da natureza e ao racismo ambiental institucional. Através da revisão bibliográfica, ressaltamos a importância dos estudos e práticas decoloniais e do desenho autônomo para a descolonização da natureza e, de modo mais geral, dos espaços subalternizados pela colonialidade, em suas mais diversas formas.

PALAVRAS-CHAVE:

desenho; desenvolvimento; natureza;

decolonialidade.

\begin{abstract}
:
We first seek to approach the concept of development in decoloniality, with emphasis on the various forms of colonialism aimed at the destruction of nature and non-dualistic ways of life. From this, we salvaged the notion of design from Arturo Escobar that compares relational and dualistic ontology, relating these concepts to development in colonialism, (which is) the destruction of nature and institutional environmental racism. Through bibliographic review, we emphasize the importance of decolonial studies and practices, and autonomous design for the decolonization of nature and, more generally, of spaces subalternated by coloniality, in their most diverse forms.
\end{abstract}

KEYWORDS: drawing; development; nature; decoloniality. 


\section{INTRODUÇÃO}

Neste estudo defendemos, primeiramente, que o eurocentrismo e a noção de desenvolvimento são elementos indissociáveis e constituintes da modernidade/colonialidadel. Depois, resgatamos os conceitos de raça em Quijano, colonialidade do conhecimento e da subjetividade, colonialidade do saber e do ser, necessárias para o fazer desenvolvimentista eurocêntrico e, consequentemente, para a destruição da natureza e de culturas inteiras em Abya Yala ${ }^{2}$.

A partir das questões apresentadas no primeiro tópico, é introduzida a discussão sobre desenho a partir das formulações de Arturo Escobar. Nesse cenário, visamos diferenciar ontologias dualista e relacional, apontando para a crítica ao papel da ontologia dualista nos desenhos de Abya Yala e no racismo ambiental institucional.

De modo geral, o intuito da pesquisa é entendermos o desenvolvimento na colonialidade a partir das categorias teórico-conceituais trazidas pela proposta decolonial desde uma perspectiva crítica. Além do mais, buscamos evidenciar a importância do desenho autônomo e da decolonialidade através das lutas ontológicas e epistemológicas, principalmente relacionadas à natureza.

\section{DESENVOLVIMENTO NA COLONIALIDADE}

Existem diversas interpretações sobre o conceito de desenvolvimento em termos científicos. É válido frisar que este estudo se propõe a abordar a noção de desenvolvimento a partir de referenciais decoloniais. Desse modo, se aproxima de uma leitura crítica das implicações dessa concepção, elucidadas nas perspectivas teóricas apresentadas ao longo deste artigo.

Nos moldes modernos 3 , a compreensão sobre o que é ser desenvolvido ou não é indissociável do eurocentrismo. Para Dussel ${ }^{4}$, o eurocentrismo é um elemento indissociável da falácia desenvolvimentista. Ou seja, constitui e é constituído por essa falácia. O autor sugere que os parâmetros para se alcançar determinado nível

\footnotetext{
1 Para uma melhor compreensão desse conceito, ler Escobar (2004). Indicamos também Restrepo e Rojas (2010) para uma introdução à proposta decolonial.

20 caráter decolonial presente neste trabalho aponta para a importância de questionar a validade da hegemonia cultural europeia. Dessa forma, substituímos o termo América Latina por Abya Yala em uma tentativa, ainda que simbólica, de problematizar a ideia de América Latina.

3 Para Mignolo (2010) modernidade é a retórica da colonialidade.

4 DUSSEL, Enrique. 1492 - El encubrimiento del otro. Hacia el origen del "mito de la Modernidad". La Paz: Plural Editores/UMSA, 1993, p. 17.
} 
de desenvolvimento obedecerá a critérios que serão definidos em uma interpretação eurocêntrica da realidade e, de modo mais contextualizado, da natureza.

É pertinente esclarecer o que se compreende por eurocentrismo, tendo em vista a utilização dessa categoria conceitual ao longo deste artigo. Para Quijano:

Não se trata, em consequência, de uma categoria que implica toda a história cognoscitiva em toda a Europa, nem na Europa Ocidental em particular. Em outras palavras, não se refere a todos os modos de conhecer de todos os europeus e em todas as épocas, mas a uma específica racionalidade ou perspectiva de conhecimento que se torna mundialmente hegemônica colonizando e sobrepondo-se a todas as demais, prévias ou diferentes, e a seus respectivos saberes concretos, tanto na Europa como no resto do mundo. 5

Nesse ponto, este trabalho não se pré-dispõe a realizar uma generalização infundada da realidade europeia nem, tampouco, sugerir que a Europa é um espaço ontologicamente homogêneo. O que está em questão aqui é a configuração hegemônica que se constrói a partir desse espaço geográfico e epistemológico em termos de saberes e as implicações disso para outras formas de racionalidade e conhecimento sobre a natureza, principalmente em Abya Yala.

A partir disso, Wallerstein6, propõe que o eurocentrismo é expresso nas Ciências Sociais de, pelo menos, cinco modos. Aqui, é mais pertinente dois: o modo como elas pressupuseram a civilização ocidental e como determinaram impositivamente a teoria do progresso ${ }^{7}$. Civilização deve ser entendida como:

[...] um conjunto de características sociais, as quais são contrastadas com um primitivismo ou barbarismo. A Europa moderna se considera mais do que apenas uma civilização entre várias outras; ela se considera (única ou pelo menos especialmente) civilizada. ${ }^{8}$

Para muitos, essa terminologia é considerada ultrapassada e sinônimo de paradigmas interpretativos superados. Contudo, o autor pontua:

\footnotetext{
5 QUIJANO, Aníbal. Colonialidade do poder, Eurocentrismo e América Latina. In: Edgardo Lander (org). A colonialidade do saber: eurocentrismo e ciências sociais. Perspectivas latinoamericanas. Ciudad Autónoma de Buenos Aires, Argentina: Colección Sur Sur, CLACSO, 2005, p. 115.

6 WALLERSTEIN, Immanuel. O fim do mundo como concebemos: ciência social para o século XXI. Tradução de Renato Aguiar. Rio de Janeiro: Revan, 2002, p. 206.

7 A teoria do progresso em Immanuel Kant e a leitura contratualista moderna sustentam a ideia da existência de uma natureza humana. Essa natureza visa alcançar o progresso que, por sua vez, é unidirecional. Nesse viés, a natureza humana, provida da racionalidade moderna, é concebida como uma condição necessária para que se alcance o desenvolvimento/progresso. Com isso, a noção de natureza humana estabelecerá os parâmetros aceitos para o desenvolvimento, inclusive os de utilização da natureza. A esse respeito, indicamos Barros II (2014).

8 WALLERSTEIN, Immanuel. O fim do mundo como concebemos: ciência social para o século XXI. Tradução de Renato Aguiar. Rio de Janeiro: Revan, 2002, p. 209.
} 
O que deve ser sublinhado é que na época em que a categoria de civilização perdeu sua inocência e começou a atrair suspeitas (principalmente depois de 1945), a categoria de progresso sobreviveu e foi mais do que adequada para substituir a de civilização, cheirando um pouco melhor. ${ }^{9}$

Nessa continuidade, progresso e civilização adquirem a mesma conotação. Apesar do esforço empregado na mudança conceitual, leituras mais apuradas do significado desses termos não outorgam tal interpretação. Dessa maneira, o progresso, sendo uma das expressões mais evidentes do eurocentrismo, se constitui como uma peça necessária para a construção da falácia desenvolvimentista.

Outro elemento se configurará como uma das mais importantes e eficientes formas de eurocentrismo: o controle do conhecimento e da subjetividade. Para Quijano, a Europa [...] concentrou sob sua hegemonia o controle de todas as formas de controle da subjetividade, da cultura, e em especial do conhecimento, da produção do conhecimento". 10 Destarte, esse controle possibilitou com que a teoria do progresso fosse amplamente aceita cientificamente e isso significou entender a natureza de forma eurocêntrica, como um espaço suscetível de destruição para os interesses do capitalismo emergente. Significou também o entendimento do progresso/desenvolvimento exclusivamente desde uma ontologia dualista ${ }^{11}$.

Tendo em vista a eficiência da teoria do progresso aliada ao controle do conhecimento e da subjetividade, a ideia de raça reforça essa perspectiva desenvolvimentista imersa na colonialidade e, prioritariamente, serve como elemento necessário para a naturalização da inferiorização biológica de povos não brancos.

Dentro dessa perspectiva, há igualmente a manutenção da ideia de que povos não brancos são naturalmente desprovidos dos requisitos para o desenvolvimento, por serem, inclusive, desprovidos de cultura e próximos da

\footnotetext{
9 WALLERSTEIN, Immanuel. O fim do mundo como concebemos: ciência social para o século XXI. Tradução de Renato Aguiar. Rio de Janeiro: Revan, 2002, p. 214.

10 QUIJANO, Aníbal. Colonialidade do poder, Eurocentrismo e América Latina. In: Edgardo Lander (org). A colonialidade do saber: eurocentrismo e ciências sociais. Perspectivas latinoamericanas. Ciudad Autónoma de Buenos Aires, Argentina: Colección Sur Sur, CLACSO, 2005, p. 110.

11 Esse conceito será desenvolvido no próximo tópico.
} 
selvageria/natureza 12. Para Quijano 13, a ideia de raça se configurou como critério básico de classificação social hierárquico, permitindo a constituição do novo padrão de poder ${ }^{14}$ mundial capitalista a partir da exploração de negros, indígenas e da própria natureza.

Essa classificação se amparava na diferença fenotípica e genotípica entre brancos e não brancos e, com isso, na construção, pelos primeiros, de uma suposta inferioridade dos últimos. Adicionalmente, a ideia de raça provou ser, como mencionado, um instrumento mais do que suficiente para sustentar a ideia de desenvolvimento em seu sentido moderno. Em termos de Quijano:

No próprio começo da América, se estabelece a ideia de que existem diferenças de natureza biológica dentro da população do planeta, associadas necessariamente a capacidade de desenvolvimento cultural, mental em geral. [...] E a prolongada prática colonial de dominação/exploração fundada sobre tal pressuposto, enraizou e legitimou essa ideia perduravelmente. Desde então, as velhas ideias de superioridade - inferioridade implicadas em toda relação de dominação, inclusive meramente burocrática, ficaram associadas a natureza, foram naturalizadas para toda a história seguinte. ${ }^{15}$

Dentro dessa interpretação, o discurso eurocêntrico contido na ideia de raça naturaliza a ideia de que alguns indivíduos são naturalmente inferiores e, por isso, não cumprem com os requisitos básicos para o desenvolvimento.

Se, por um lado, a ideia de raça, imersa em uma leitura eurocêntrica do desenvolvimento, foi proposta por um conhecimento que se fez universal e que foi capaz de, inclusive, colonizar o próprio ser, por outro, a colonialidade do saber servirá como uma categoria conceitual imprescindível para o fazer desenvolvimentista moderno/colonial em termos epistemológicos.

A colonialidade do saber é fruto da modernidade e legitimou o eurocentrismo, situando o saber científico ocidental como superior a todas as outras formas de saber. Lander defende que, dentro desse discurso, "[...] se

\footnotetext{
12 Nesse ponto, resgatamos novamente essa interpretação dualista de natureza/civilização. Como abordado em Wallerstein (2002), essa ideia ainda se mantém na teoria do progresso/desenvolvimento e subdesenvolvimento.

13 QUIJANO, Aníbal. Colonialidade do poder, Eurocentrismo e América Latina. In: Edgardo Lander (org). A colonialidade do saber: eurocentrismo e ciências sociais. Perspectivas latinoamericanas. Ciudad Autónoma de Buenos Aires, Argentina: Colección Sur Sur, CLACSO, 2005, p. 108.

14 A ideia de raça é um elemento constitutivo do que Quijano (1992) chama de colonialidade do poder. É válido frisar a importância da contribuição do feminismo decolonial para o enriquecimento do conceito de colonialidade do poder.

15 QUIJANO, Aníbal. ¡Qué tal raza! Ecuador Debate. Ełnicidades e identificaciones, Quito: Ecuador, $n^{\circ} .48$, p. 141-152, 1999, p. 148-149.
} 
compreende somente uma modernidade do saber - o saber científico ocidental como o conhecimento verdadeiro, universal e objetivo".16 O autor recorda também que a dita modernidade, concebida como processo intra-europeu, é fruto de

[...] uma história que des-historiza, que oculta as relações constitutivas do sistema-mundo colonial moderno. [...] a partir dos pressupostos básicos do eurocentrismo, se naturaliza a ordem da sociedade liberal capitalista. ${ }^{17}$

Portanto, o desenvolvimento adquire uma dimensão estritamente capitalista. Ainda nessa perspectiva, Escobar ressalta:

Uma antropologia da modernidade centrada na economia nos leva a questionar as fábulas do mercado, a produção e o emprego que sustentam o que poderia ser chamado de a economia ocidental. Essas fábulas são raramente questionadas e são consideradas formas normais e naturais de ver a vida, a forma de ser das coisas. ${ }^{18}$

Ora, se a ordem liberal é concebida pelo saber econômico ocidental e eurocêntrico como um modo de economia transcendente a todos os outros modos na história do mundo, o capitalismo é naturalizado e tido como suscetível de todas as formas de sociedade que tenham as potencialidades para se alcançar o desenvolvimento. Ou seja, que detenham a verdade estabelecida pelo saber científico ocidental e que possam explorar a natureza até as últimas consequências.

Como abordado, é também a partir desse saber científico que as ciências sociais se constituirão e outorgarão legitimidade ao conhecimento como ferramenta de controle sobre a natureza. Em concordância com Lander:

Com as ciências sociais dá-se o processo de cientifização da sociedade liberal, sua objetivação e universalização e, portanto, sua naturalização. 0 acesso à ciência, e a relação entre ciência e verdade em todas as disciplinas, estabelece uma diferença radical entre as sociedades modernas ocidentais e o restante do mundo. Dá-se, como aponta Bruno Latour, uma diferenciação básica entre uma sociedade que possui a

\footnotetext{
16 LANDER, Edgardo. Eurocentrismo, saberes modernos y naturalización del orden global del capital. In: DUBE, Saurabh et al. (coord.). Modernidades coloniales: otros pasados, historias presentes. México: El Colegio de México, Centro de Estudios de Asia y África, 2004, p. 206.

17 LANDER, Edgardo. Eurocentrismo, saberes modernos y naturalización del orden global del capital. In: DUBE, Saurabh et al. (coord.). Modernidades coloniales: otros pasados, historias presentes. México: El Colegio de México, Centro de Estudios de Asia y África, 2004, p. 206.

18 ESCOBAR, Arturo. La invención del tercer mundo. Construcción y deconstrucción del desarrollo. Traducción de Diana Ochoa. Caracas: Fundación Editorial el perro y la rana, 2008, p. 108.
} 
verdade - o controle da natureza - e outras que não o têm. ${ }^{19}$

A observação do autor permite uma afirmação de que a retroalimentação entre o eurocentrismo das Ciências Sociais ocidentais e o desenvolvimento na colonialidade convergem para uma proposta explícita de controle/destruição da natureza e dos povos que habitam esses espaços.

Em decorrência da naturalização da ordem neoliberal, os parâmetros para se pensar o desenvolvimento passam a ser definidos por uma lógica de relações econômicas a partir da ontologia dualista. Escobar resgata que

Através das práticas, as ontologias criam verdadeiros mundos. Por exemplo,
a incorporação de premissas sobre o caráter separado da natureza, assim
como a forma de pensar em economia e alimentação leva à forma de
agricultura do monocultivo (em contraste, uma ontologia relacional leva a
uma forma de cultivo diverso e integral, como demonstra a agroecologia
para muitos sistemas de fazenda camponeses ou indígenas).20

Nesse sentido, o espaço rural21, elemento transversal na proposta deste estudo, experimentou a colonialidade da natureza, principalmente, mas não exclusivamente, através da intensiva tecnificação22 moderna da agricultura monocultora, das paisagens e dos desenhos advindos dessa prática.

A justificativa da colonialidade da natureza na agricultura perpassa diversas dimensões, principalmente no sentido de, supostamente, garantir alimentação. Isso implicará nos desenhos e paisagens modernas, rurais e não rurais, no âmbito de Abya Yala. Esse tema será abordado no próximo tópico. De qualquer modo, o que deve ficar evidente dentro do tópico atual é a relação entre desenvolvimento e eurocentrismo e como essa relação pressupõe diversas violências e dinâmicas de saber e poder que estão naturalizadas dentro da perspectiva da colonialidade.

19 LANDER, Edgardo. A colonialidade do saber: eurocentrismo e ciências sociais. Perspectivas latinoamericanas. Ciudad Autónoma de Buenos Aires, Argentina: Colección Sur Sur, CLACSO, 2005, p. 14.

20 ESCOBAR, Arturo. Sentipensar con la tierra: nuevas lecturas sobre desarrollo, territorio y diferencia. Medellín: Ediciones UNAULA, 2014, p. 58.

21 Esse estudo não compreende o rural de forma dicotômica ou como um espaço homogêneo. Existe uma narrativa hegemônica sobre o espaço rural, construída pela ontologia dualista. Isso estará mais claro no próximo tópico. Apesar disso, nesse estudo, a colonialidade da natureza não se limita ao espaço rural.

22 Esse projeto respondeu a uma agenda estritamente liberal, principalmente focada nas relações exteriores no que se refere às pautas emergentes sobre insegurança alimentar. Além disso, a partir desse processo de tecnificação, é naturalizada a ideia de que o espaço rural é sinônimo de produção agrícola. Essas questões serão melhores abordadas no próximo tópico deste texto. 


\section{DESENHO E PAISAGENS RURAIS EM ABYA YALA}

Compreendendo o desenvolvimento na colonialidade através dos referenciais selecionados, este tópico é direcionado para uma abordagem da colonialidade da natureza a partir do conceito de desenho proposto por Escobar, com ênfase no espaço rural. Assim, utiliza conceitos como desenho, ontologia relacional e racismo ambiental institucional para tal abordagem.

Há mais de 500 anos, Abya Yala vem sendo sequestrada pelo discurso colonial. As implicações disso para a natureza, espaço rural e culturas locais são devastadoras desde uma leitura da colonialidade. Escobar argumenta que:

O modo mais adequado para acessar a questão do desenho é ontológico. Desenhar este modo de acesso implica examinar criticamente a ontologia dualista de separação, controle e apropriação que se voltou dominante com a modernidade patriarcal capitalista Ocidental e se perguntar sobre a existência e criação potencial de outras racionalidades e modos de ser, sobretudo aqueles que enfatizam a profunda relacionalidade e a interconexão de tudo o que existe. ${ }^{23}$

Apesar da primeira experiência de Escobar com o tema do desenho se dar na esfera da engenharia química, a compreensão de desenho para o autor é influenciada, primeiramente, pela contribuição de Goodwin'24 e Maturana e Varela25 sobre auto-organização, autopoiesis e complexidade. Posteriormente, e majoritariamente, sua concepção de desenho segue uma linha mais ecológica chamada de ontologia política e desenho ontológico ${ }^{26}$. Desse modo, a discussão sobre desenho 27 implica necessariamente na diferenciação entre ontologia dualista e ontologia relacional. Esses conceitos serão desenvolvidos posteriormente e estão intrinsecamente relacionados à colonialidade da natureza e com o modo como as paisagens rurais foram constituídas dentro dessa perspectiva.

Retomando a questão do desenho, é importante que fique evidente o entendimento desse conceito para o autor. Escobar ${ }^{28}$ recapitula como as

\footnotetext{
23 ESCOBAR, Arturo. Autonomía y diseño: la realización de lo comunal. Traducción de Cristóbal Gnecio. Popaýan: Editorial Universidad del Cauca, 2016, p. 43.

${ }^{24}$ GOODWIN, Brian. How the leopard changed its spots: the evolution of complexity. Princeton: Princeton University Press, 1994.

25 MATURANA, Humberto; VARELA, Francisco. Autopoiesis and cognition: the realization of the living. Boston: Reidel Publishing Company, 1980.

26 WINOGRAD, Terry; FLORES, Fernando. Understanding computers and cognition: a new foundation for design. Norwood, NJ: Ablex Publishing Corporation, 1986.

27 Para mais informações ler o prefácio de Escobar, 2016.

28 ESCOBAR, Arturo. Autonomía y diseño: la realización de lo comunal. Traducción de Cristóbal Gnecio. Popaýan: Editorial Universidad del Cauca, 2016, p. 25-26.
} 
abordagens sobre desenho vêm sendo feitas na última década, apontado para algumas questões importantes. Em síntese, essas abordagens resgatam uma concepção de desenho como ubíquo e sugerem uma visão do desenho desde elementos ambientais e culturais. Apesar disso, o autor ressalta:

Ainda está em questão se tudo isso permitirá afirmar que surgiu uma nova cultura de desenho, ainda que seja importante levar em conta o agudo sentido da mudança nos estudos críticos do desenho e um compromisso sustentado com essa mudança por parte de certos teóricos do desenho..$^{29}$

Nesse viés, o trabalho se desenvolve a partir do entendimento de que todos nós desenhamos ${ }^{30}$. Além disso, pretende relacionar a prática do desenho autônomo à ontologia relacional e à pluriversalidade.

Essa leitura é fundamental para uma interpretação não eurocêntrica da realidade e, por conseguinte, para a reorientação das dinâmicas e paisagens rurais aniquiladas pela colonialidade da natureza. Entender o desenho ou o desenhar como um processo possível desde culturas subalternizadas pela colonialidade do poder, saber e ser e para além da colonialidade da natureza é também romper, paulatinamente, com uma ontologia dualista, propalada pelo eurocentrismo, em suas mais diversas formas.

Nesse momento, cabe diferenciar dois conceitos importantes: ontologia relacional e dualista. É, exclusivamente, devido a um arcabouço teórico da separação entre sujeito e natureza, cultura e barbárie/natureza ou desenvolvimento/progresso e subdesenvolvimento que a ontologia dualista se sustenta. Para Escobar,

Na perspectiva em questão, ontologia se refere àquelas premissas que os
diversos grupos sociais mantêm sobre as entidades que realmente existem
no mundo. Assim, por exemplo, na ontologia moderna - chamada dualista
pois se baseia na separação franca entre natureza e cultura, mente e
corpo, ocidente e o resto, etc. - o mundo está povoado por indivíduos que
manipulam objetos e se movem em mercados, todos autoconstituídos e
autorregulados. Em outras palavras, dentro de uma ontologia dualista, nos
vemos como sujeitos autossuficientes que confrontamos ou vivemos em um
mundo composto de objetos igualmente autossuficientes que podemos
manipular com liberdade. ${ }^{31}$

Nessa leitura, ao prever a dissociabilidade entre sujeito e qualquer outra

29 ESCOBAR, Arturo. Autonomía y diseño: la realización de lo comunal. Traducción de Cristóbal Gnecio. Popaýan: Editorial Universidad del Cauca, 2016, p. 26.

30 ESCOBAR, Arturo. Autonomía y diseño: la realización de lo comunal. Traducción de Cristóbal Gnecio. Popaýan: Editorial Universidad del Cauca, 2016, p. 26.

${ }^{31}$ ESCOBAR, Arturo. Sentipensar con la tierra: nuevas lecturas sobre desarrollo, territorio y diferencia. Medellín: Ediciones UNAULA, 2014, p. 57-58. 
coisa, a ontologia dualista permite que o sujeito se aproprie do meio ambiente sem se reconhecer como parte do mesmo, o que, quando levado às últimas consequências nos moldes modernos/eurocêntricos e neoliberais, acarreta em problemas ambientais e culturais irreversíveis. Ou seja, na destruição do meio ambiente e de culturas inteiras 32 .

Para a ontologia relacional, por outro lado, não existem separações dualistas e tudo se inter-relaciona:

Um princípio geral que me parece útil é que uma ontologia relacional é aquela dentro da qual nada preexiste às relações que as constituem. Nessas ontologias a vida é inter-relação e interdependência do princípio ao fim, sempre e em todo o momento. [...]. Esse princípio de interser tem sido amplamente desenvolvido no pensamento budista, mas, como venho insistido, também caracteriza de fato muitas tradições culturais históricas. ${ }^{33}$

Após esse fragmento fica mais evidente a diferença entre ontologia relacional e dualista. No contexto da colonialidade da natureza, enquanto uma ontologia opera em um paradigma estritamente dualista, a outra exacerba os limites da separação entre natureza e cultura ao propor a indissociabilidade dessas esferas.

A ontologia dualista certamente esteve presente em grande parte dos desenhos tipicamente modernos. No espaço rural, o discurso do desenvolvimento privilegiou "o desenvolvimento agrícola baseado em extensas fazendas mercantilizadas e no uso de insumos químicos". 34 A partir disso, a intensiva tecnificação da agricultura/colonialidade da natureza 35 foi inquestionavelmente eficiente em desenhar somente um rural possível: o de monocultivo.

A naturalização e redução do espaço rural, em suas mais diversas formas de paisagem e existência, a um espaço voltado exclusivamente para a produção agrícola certamente é fruto da ontologia dualista. Aliás,

Muitos aspectos da vida se converteram cada vez mais economizados, incluindo a biologia humana, o mundo natural não humano, as relações entre as pessoas, e as relações entre elas e a natureza. As linguagens da vida diária foram totalmente invadidas pelos discursos da produção pelo

\footnotetext{
32 Retornaremos a essa questão ao me valer do conceito de racismo ambiental. Esse conceito é proposto em MORAES; SILVA, 2019.

33 ESCOBAR, Arturo. Autonomía y diseño: la realización de lo comunal. Traducción de Cristóbal Gnecio. Popaýan: Editorial Universidad del Cauca, 2016, p. 121.

34 ESCOBAR, Arturo. La invención del tercer mundo. Construcción y deconstrucción del desarrollo. Traducción de Diana Ochoa. Caracas: Fundación Editorial el perro y la rana, 2008, p. 84.

35 Maluf $(2011$, p. 20) afirma que a insegurança alimentar a nível global não decorre de um problema de produção de alimentos e sim de distribuição em quantidade, qualidade, e adequação socioambiental desse alimento. Além disso, práticas mais sólidas relacionadas a Soberania Alimentar dependem de drásticas transformações nesse paradigma.
} 
mercado. 36

Desse modo, "[...] conhecimento científico e o desenvolvimento tecnológico avançam em uma direção linear ascendente para níveis cada vez superiores no saber e na capacidade de transformação útil da natureza". 37 Na perspectiva da colonialidade da natureza, essa transformação só é útil através do aparato ontológico dualista. Sendo assim, é inútil transformar a natureza a partir de outras formas de ontologia e possibilidades de desenho.

Um aspecto fundamental da ontologia dualista em Abya Yala é a noção de racismo ambiental e a valorização de dinâmicas eurocêntricas em detrimento do resgate e reconhecimento cultural e territorial de povos subalternizados.

A exploração e destruição da natureza seja pela expansão do agronegócio com monoculturas transgênicas, seja para exploração de mineradoras ou construção de megaprojetos desenvolvimentistas [...] gera conflitos socioambientais que são endossados pelo Estado, o que caracteriza o racismo ambiental institucional.38

O racismo ambiental, portanto, está orientado para a institucionalização das violências contra comunidades indígenas e quilombolas a partir de um paradigma desenvolvimentista que fortalece interesses neoliberais e negligencia outros. Os autores resgatam o conceito de necropolítica ${ }^{39}$ como mecanismo institucional de extermínio de povos indígenas e quilombolas através do não reconhecimento e destruição de seus territórios/meios de existência.

Além da colonialidade da natureza através das monoculturas, outro ponto importante dentro dessa proposta é o histórico das mineradoras em Abya Yala. Para Teubal e Palmisano,
A partir do descobrimento das minas de prata de Cerro Rico em Potosí em 1545, um dos depósitos de prata mais importantes do mundo, se produz uma reestruturação do sistema de acumulação para responder à lógica de expansão das ambições imperiais de Castilha. Este sistema foi insustentável desde seu início porque envolveu uma vasta desflorestação, destruição da produção agrícola indígena, inundações catastróficas, expansão da fome, instauração de insegurança alimentar estrutural,

\footnotetext{
36 ESCOBAR, Arturo. La invención del tercer mundo. Construcción y deconstrucción del desarrollo. Traducción de Diana Ochoa. Caracas: Fundación Editorial el perro y la rana, 2008, p. 110.

37 LANDER, Edgardo. Eurocentrismo, saberes modernos y naturalización del orden global del capital. In: DUBE, Saurabh et al. (coord.). Modernidades coloniales: otros pasados, historias presentes. México: El Colegio de México, Centro de Estudios de Asia y África, 2004, p. 206.

38 MORAES, Oriel Rodrigues de; SILVA, Liana Amin Lima da. Racismo Ambiental, Colonialismos e Necropolítica: direitos territoriais quilombolas subjugados no Brasil. In: LIMA, Fonseca Emanuel et al. (org.). Ensaios Sobre Racismos. Pensamento de Fronteira. São José do Rio Preto, SP: Balão Editorial, 2019, p. 33-34.

39 Esse conceito é proposto em Mbembe (2016).
} 
deslocamento e relocalização de mais de um milhão de pessoas [...].40

Essa abordagem evidencia o caráter sistêmico e estrutural do racismo ambiental na Bolívia e em toda a Abya Yala. É evidente também como ela serviu e ainda serve ao crescimento econômico dos países ditos desenvolvidos ao passo em que destrói saberes e práticas relacionais presentes em Abya Yala, além dos elementos naturais presentes nesse espaço e de todas as consequências alimentares advindas desse processo.

A partir do conceito de racismo ambiental institucional, as políticas de preservação ambiental também se inserem nessa configuração ontológica dualista e dicotômica entre natureza e cultura ao não reconhecerem a territorialidade de povos originários de Abya Yala e da diáspora africana.

Para além dos projetos desenvolvimentistas afetando territórios de vida, o racismo ambiental configura-se também na implementação de políticas ambientais preservacionistas que excluem os seres humanos, povos e comunidades, não reconhecendo os territórios tradicionais que esses grupos habitam, a noção de pertencimento que configura a relação intrínseca entre natureza e cultura. 41

Pensar essas políticas enquanto instrumento de negação desses meios de existência permite uma aproximação ao que Lander 42 propõe sobre economia verde. Essas narrativas embranquecem a natureza, reverberam um discurso preservacionista que não questiona as bases eurocêntricas da compreensão da natureza ao mesmo tempo em que expulsam esses povos de suas terras e, consequentemente, negam suas existências.

Retomando as discussões sobre desenvolvimento na colonialidade, a noção de raça em Quijano permite entender o racismo como elemento básico e estrutural da Abya Yala recém invadida. Os aspectos culturais de negros e indígenas não eram equivalentes ao progresso/desenvolvimento propalado por Europa. Nessa continuidade, o racismo ambiental estrutural e institucional elimina formas de vida incompatíveis com o desenvolvimento.

\footnotetext{
40 TEUBAL, Miguel; PALMISANO, Tomás. Acumulación por desposesión: la colonialidad del poder em América Latina. In: ACOSTA, Alberto et alli. Renunciar al bien común. Extractivismo y (pos)desarrollo em América Latina. Buenos Aires: Mardulce, 2012, p. 136.

${ }^{41}$ MORAES, Oriel Rodrigues de; SILVA, Liana Amin Lima da. Racismo Ambiental, Colonialismos e Necropolítica: direitos territoriais quilombolas subjugados no Brasil. In: LIMA, Fonseca Emanuel et al. (org.). Ensaios Sobre Racismos. Pensamento de Fronteira. São José do Rio Preto, SP: Balão Editorial, 2019, p. 41.

42 LANDER, Edgardo. La Economía Verde: el lobo se viste con piel de cordero. Amsterdam: Transnational Institute, 2011, p. 1-10.
} 
Como observado, o controle do conhecimento e da subjetividade contribuiu para a manutenção da ontologia dualista, da colonialidade da natureza e, por sua vez, do racismo ambiental. Além disso, a compreensão unidimensional da natureza, advinda da colonialidade do saber, ao fortalecer os interesses da ordem neoliberal para o desenvolvimento destruiv e ainda destrói a natureza e, consequentemente, a cultura desses povos.

Nessa leitura, a natureza e a cultura são separadas e as narrativas, aparentemente ultrapassadas, adquirem uma ideia de civilização/progresso que não contempla outras visões culturais senão a eurocêntrica, ancorada na ontologia dualista sobre natureza e cultura, civilização/progresso e selvageria.

\begin{abstract}
O racismo ambiental que encontramos nos países e regiões periféricas neste século XXI, reafirma a vocação etnocida das práticas racistas de assimilação e extermínio. Para além da invisibilidade das políticas que ignoram os povos, estamos diante da perversidade de um modelo que expressamente cultua o desaparecimento de minorias étnicas, que são vistas como obstáculos para o des-envolvimento. Os territórios de vida, quando não em sua totalidade afundados em lama tóxica da mineração ou alagados por um reservatório hidrelétrico, ilhados, gritam por socorro. Natureza e cultura se fundem, retornam para a indissociabilidade inerente que a modernidade insiste em separar. Aos gritos e prantos de sobrevivência, junto à resistência e re-existência dos povos indígenas, quilombolas e tradicionais, escutamos os gritos de socorro dos rios mortos, da fauna, flora e da totalidade da vida usurpada. 43
\end{abstract}

Apesar de toda a perversidade histórica etnocida do racismo ambiental, há re-existência e lutas ontológicas de povos subalternizados, principalmente pela colonialidade da natureza, em defesa de suas existências e, assim, da existência da própria natureza.

O não reconhecimento ou destruição de um território indígena ou quilombola implica também no extermínio desses povos, "[...] pois a existência de uma comunidade tradicional depende de sua territorialidade [...]". ${ }^{44} \mathrm{~A}$ noção de racismo ambiental contribui para o desvelamento de posturas institucionais para 0 desenho de determinada paisagem. Ao optar pela ontologia dualista, o desenho constitucional cria paisagens que respondem a interesses de mercado, que

43 MORAES, Oriel Rodrigues de; SILVA, Liana Amin Lima da. Racismo Ambiental, Colonialismos e Necropolítica: direitos territoriais quilombolas subjugados no Brasil. In: LIMA, Fonseca Emanuel et al. (org.). Ensaios Sobre Racismos. Pensamento de Fronteira. São José do Rio Preto, SP: Balão Editorial, 2019, p. 42.

${ }^{4}$ MORAES, Oriel Rodrigues de; SILVA, Liana Amin Lima da. Racismo Ambiental, Colonialismos e Necropolítica: direitos territoriais quilombolas subjugados no Brasil. In: LIMA, Fonseca Emanuel et al. (org.). Ensaios Sobre Racismos. Pensamento de Fronteira. São José do Rio Preto, SP: Balão Editorial, 2019, p. 41. 
destroem a natureza e extermina culturas inteiras.

A noção de civilização/progresso/desenvolvimento, como observado por Gudynas45, buscou civilizar não só a natureza, mas tudo aquilo que era considerado selvagem. Nesse cenário, culturas consideradas selvagens deveriam ser úteis para o desenvolvimento em uma ontologia dualista, ainda que essa utilidade significasse a destruição ${ }^{46}$ dessas culturas. $O$ racismo ambiental é, certamente, um exemplo dessa destruição.

Após essa breve reflexão sobre a ontologia dualista, o conceito de pluriversalidade será fundamental para as reflexões finais propostas pelo artigo. Para Escobar

[...] a perseverança das comunidades, os comuns e as lutas por sua defesa e reconstrução - particularmente, mas não exclusivamente, as que incorporam, explicitamente, dimensões etnoterritoriais - implicam resistência e a defesa de territórios que, no melhor e mais radical dos casos, pode ser descrito como pluriversal, ou seja, como o fenômeno da coexistência de múltiplos mundos. Ao resistir ao projeto neoliberal de globalização muitas comunidades indígenas, afrodescendentes, camponesas e urbanas pobres estão promovendo lutas ontológicas. 47

Desse modo, entender os territórios como pluriversais é também contemplar outras formas de ontologia. Dentro dessa perspectiva, a ontologia relacional se mostra cada vez mais necessária em contraposição à colonialidade da natureza e das paisagens rurais a partir da ontologia dualista e, de modo mais amplo, de toda a modernidade na busca pelo desenvolvimento.

Escobar48 resgada o exemplo de Tumaco, na Colômbia, para enfatizar o papel dos desertos verdes na substituição dos diversos mundos paisagísticos e comunais presentes naquele espaço. Apesar da especificidade geográfica, o autor afirma que essa realidade é bem próxima dos territórios rurais em Abya Yala. Para ele:

Dois aspectos importantes devem ser destacados nessa mudança dramática: em primeiro lugar, a forma de plantação apaga as relações mantidas com e pelo mundo dos bosques; a plantação, que surgiu de uma ontologia dualista de dominação humana sobre a natureza, é um dos meios

\footnotetext{
45 GUDYNAS, Eduardo. Ecología, economía y etica del desarrollo sostenible. Montevideo: CLAES Centro Latino Americano de Ecología Social, 2004, p. 13.

46 Indicamos relacionar este ponto com a noção de mestiçagem como discurso de poder em Walsh (2009).

47 ESCOBAR, Arturo. Autonomía y diseño: la realización de lo comunal. Traducción de Cristóbal Gnecio. Popaýan: Editorial Universidad del Cauca, 2016, p. 86.

48 ESCOBAR, Arturo. Autonomía y diseño: la realización de lo comunal. Traducción de Cristóbal Gnecio. Popaýan: Editorial Universidad del Cauca, 2016, p. 86.
} 
mais eficazes para mudar a ocupação ontológica de mundos relacionais. ${ }^{49}$

Aqui, a agricultura de monocultivo executa uma função importante no apagamento de formas relacionais de se entender a natureza e, consequentemente, de desenhar desde outras referências e com outros olhares para com o meio e o outro.

A partir disso, é prudente alertar para a necessidade do desenho autônomo aceitando, principalmente, a premissa de que todo desenho deve pressupor a autonomia de saber de cada comunidade bem como sua capacidade de entender e desenhar a própria realidade.50 Desde a ontologia relacional e do pluriverso, o desenho autônomo frisaria, por exemplo, outras formas de lidar com a natureza e o entendimento de diversos mundos colidentes.

Uma proposta decolonial do desenho também implica em uma urgente mudança paradigmática para a contemplação de diversas insurgências nos desenhos de Abya Yala. Afinal de contas,

Um paradigma outro, que emerge e germina desde a perspectiva da colonialidade, que busca coalizões constantes da diferença colonial, em que se resistem à globalização localizada e à localização globalizada tanto de direita como de esquerda, contribui ao cosmopolitismo crítico precisamente por fomentar uma consciência da diferença de perspectivas na compatibilidade de projetos ${ }^{11}$ : a emancipação, a libertação, a descolonização. ${ }^{52}$

Colocar o desenho autônomo em evidência é também reorientar toda uma perspectiva ontológica que permeou Abya Yala durante séculos e que sustentou a falácia desenvolvimentista eurocêntrica. Essa reorientação abrirá caminhos para a decolonialidade da natureza, para o resgate da diversidade paisagística rural e natural e para a autonomia de saberes e práticas que foram impossibilitadas historicamente pela modernidade.

\section{CONCLUSÃO}

\footnotetext{
49 ESCOBAR, Arturo. Autonomía y diseño: la realización de lo comunal. Traducción de Cristóbal Gnecio. Popaýan: Editorial Universidad del Cauca, 2016, p. 86-87.

50 ESCOBAR, Arturo. Autonomía y diseño: la realización de lo comunal. Traducción de Cristóbal Gnecio. Popaýan: Editorial Universidad del Cauca, 2016, p. 202.

51 Desenho e projeto devem ser entendidos como sinônimos.

52 MIGNOLO, Walter. Historias locales/diseños globales. Colonialidad, conocimientos subalternos y pensamiento fronterizo. Traducción de Juanmari Madariaga y Cristina Vega Solís. Madrid: Ed. Akal, 2003, p. 57.
} 
O desenvolvimento moderno/colonial é eurocêntrico e implica necessariamente na destruição da natureza, de saberes e formas não dualistas de lidar com esse espaço e no extermínio de culturas inteiras Abya Yala, principalmente a serviço dos interesses da ordem liberal. Portanto, conclui-se que as diversas formas de colonialidade são imprescindíveis dentro dessa proposta eurocêntrica na construção do sistema mundo/moderno colonial proposto por Quijano e Wallerstein.

A pesquisa conclui, ainda, a necessidade da ontologia dualista para $\circ$ desenho moderno e, consequentemente, para a homogeneização do espaço natural, principalmente através do monocultivo. É importante concluir que a colonialidade da natureza implica, para além da destruição da natureza, na destruição de culturas que existem a partir desses espaços e isso é evidenciado na noção de racismo ambiental.

Por fim, o desenvolvimento eurocêntrico a partir da colonialidade da natureza e da ontologia dualista cria desenhos que destroem a natureza e povos providos de outras formas de compreender o espaço natural e não natural. É urgente, portanto, a descolonização e a reorientação da ontologia dualista dos desenhos no cenário de Abya Yala.

\section{REFERÊNCIAS BIBLIOGRÁFICAS}

BARROS, João, Progresso e raça - lluminismo e Descolonialidade epistémica, Kalágatos, Fortaleza, v. 11, n. 22, p. 319-350, 2014. Disponível em: http://kalagatos.com.br/index.php/kalagatos/article/view/201/409. Acesso em 12 ago 2018.

DUSSEL, Enrique. 1492 - El encubrimiento del otro. Hacia el origen del "mito de la Modernidad". La Paz: Plural Editores/UMSA, 1993.

ESCOBAR, Arturo. Autonomía y diseño: la realización de lo comunal. Traducción de Cristóbal Gnecio. Popaýan: Editorial Universidad del Cauca, 2016.

ESCOBAR, Arturo. La invención del tercer mundo. Construcción y deconstrucción del desarrollo. Traducción de Diana Ochoa. Caracas: Fundación Editorial el perro y la rana, 2008.

ESCOBAR, Arturo. Mundos y conocimientos de otro modo. El programa de investigación de modernidad/colonialidad latinoamericano. Bogotá: Revista Tabula Rasa, n. 1, dez. 2003, p. 51-86. Disponível em: http://www.revistatabularasa.org/numerol/escobar.pdf. Acesso em fev 2018. 
ESCOBAR, Arturo. Sentipensar con la tierra: nuevas lecturas sobre desarrollo, territorio y diferencia. Medellín: Ediciones UNAULA, 2014.

GOODWIN, Brian. How the leopard changed its spots: the evolution of complexity. Princeton: Princeton University Press, 1994.

GUDYNAS, Eduardo. Ecología, economía y etica del desarrollo sostenible. Montevideo: CLAES - Centro Latino Americano de Ecología Social, 2004.

LANDER, Edgardo. A colonialidade do saber: eurocentrismo e ciências sociais. Perspectivas latinoamericanas. Ciudad Autónoma de Buenos Aires, Argentina: Colección Sur Sur, CLACSO, 2005. p. 8-23. Disponível em: http://e disciplinas.usp.br/pluginfile.php/2591382/mod_resource/content/1/colonialidade do saber eurocentrismo ciencias sociais.pdf. Acesso em ago 2018.

LANDER, Edgardo. Eurocentrismo, saberes modernos y naturalización del orden global del capital. In: DUBE, Saurabh et al. (coord.). Modernidades coloniales: otros pasados, historias presentes. México: El Colegio de México, Centro de Estudios de Asia y África, 2004, p. 259-283.

LANDER, Edgardo. La Economía Verde: el lobo se viste con piel de cordero. Amsterdam: Transnational Institute, 2011, p. 1-10. Disponível em: https://www.tni.org/files/download/green-economy es.pdf. Acesso em abr 2019.

MALUF, Renato. Segurança Alimentar e Nutricional. Petrópolis: Editora Vozes, 2011.

MATURANA, Humberto; VARELA, Francisco. Autopoiesis and cognition: the realization of the living. Boston: Reidel Publishing Company, 1980.

MBEMBE, Achille. Necropolítica. Arte \& Ensaios, v. 32, 2016, p. 123-151. Disponível em: https://revistas.ufrj.br/index.php/ae/article/view/8993/7169. Acesso em mai 2020.

MORAES, Oriel Rodrigues de; SILVA, Liana Amin Lima da. Racismo Ambiental, Colonialismos e Necropolítica: direitos territoriais quilombolas subjugados no Brasil. In: LIMA, Fonseca Emanuel et al. (org.). Ensaios Sobre Racismos. Pensamento de Fronteira. São José do Rio Preto, SP: Balão Editorial, 2019, p. 33-49.

MIGNOLO, Walter. Desobediencia epistémica: Retórica de la modernidad, lógica de la colonialidad y gramática de la descolonialidad. Buenos Aires: Del Signo, 2010.

MIGNOLO, Walter. Historias locales/diseños globales. Colonialidad, conocimientos subalternos y pensamiento fronterizo. Traducción de Juanmari Madariaga y Cristina Vega Solís. Madrid: Ed. Akal, 2003.

QUIJANO, Aníbal. ¡Qué tal raza! Ecuador Debate. Etnicidades e identificaciones, Quito: Ecuador, $n^{\circ}$. 48, p. 141-152, 1999. Disponível em: http://repositorio.flacsoandes.edu.ec/bitstream/10469/5724/1/RFLACSO-ED48-09Quijano.pdf. Acesso em jan 2020.

QUIJANO, Aníbal. Colonialidade do poder, Eurocentrismo e América Latina. In: Edgardo Lander (org). A colonialidade do saber: eurocentrismo e ciências sociais. Perspectivas latinoamericanas. Ciudad Autónoma de Buenos Aires, Argentina: 
Colección Sur Sur, CLACSO, 2005, p. 107-130. Disponível em: http://e disciplinas.usp.br/pluginfile.php/2591382/mod resource/content/1/colonialidade do saber eurocentrismo ciencias sociais.pdf. Acesso em ago 2018.

QUIJANO, Aníbal. Colonialidad y Modernidad/Racionalidad. In: BONILLA, Heraclio (Comp.). Los Conquistados: 1492 y la población indígena de las Américas. Quito: Ediciones Libri Mundi, 1991, p. 437-447. Disponível em: http://pdfhumanidades.com/sites/default/files/apuntes/185-QUIJANOColonialidad-yModernidad-1992\%20copy.pdf. Acesso em set 2018.

RESTREPO, Eduardo; ROJAS, Alex. Inflexión decolonial: fuentes, conceptos y cuestionamientos. Popayán: Editorial Universidad del Cauca, 2010.

TEUBAL, Miguel; PALMISANO, Tomás. Acumulación por desposesión: la colonialidad del poder em América Latina. In: ACOSTA, Alberto et all. Renunciar al bien común. Extractivismo y (pos)desarrollo em América Latina. Buenos Aires: Mardulce, 2012, p. 131-156.

WALLERSTEIN, Immanuel. O fim do mundo como concebemos: ciência social para o século XXI. Tradução de Renato Aguiar. Rio de Janeiro: Revan, 2002.

WALSH, Catherine. Interculturalidad, Estado, Sociedad: luchas (de)coloniales de nuestra época. Quito: Universidad Andina Simón Bolívar/Ediciones Abya-Yala, 2009.

WINOGRAD, Terry; FLORES, Fernando. Understanding computers and cognition: a new foundation for design. Norwood, NJ: Ablex Publishing Corporation, 1986.

João Roberto Barros II: Dr. em Filosofia e Dr. em Ciências Sociais. Prof. do PPGICAL, do Ciclo comum de estudos e do curso de Filosofia da UNILA. Coordenador do grupo de pesquisa Biopolítica e colonialidade e do projeto de pesquisa Modernidade/colonialidade.

Lucas Monte: Formando em Desenvolvimento Rural e Segurança Alimentar pela UNILA. Bolsista do CNPq (2019-2020), tendo desenvolvido projeto de iniciação científica sobre a colonialidade.

(c) $\underset{\mathrm{EY}}{(\mathrm{P}}$

This work is licensed under a Creative Commons Attribution 4.0 International License.

cc) (i)

Este trabalho está licenciado sob uma Licença Creative Commons - Atribuição 4.0

Internacional.

Artigo recebido para publicação em: 03 de setembro de 2020.

Artigo aprovado para publicação em: 27 de novembro de 2020. 